\title{
Cross-linking Network Based on Poly(ethylene oxide): Solid Polymer Electrolyte for Room Temperature Lithium Battery
}

Yuhang Zhang ${ }^{a}$, Wei Lu ${ }^{a}$, Lina Cong ${ }^{a}$, Jia Liu ${ }^{a}$, Liqun Sun ${ }^{a}$, Alain Mauger ${ }^{b}$, Christian M. Julien $^{b}$, Haiming Xie ${ }^{a^{*}}$, and Jun Liu ${ }^{a^{* * *}}$

${ }^{a}$ National \& Local United Engineering Laboratory for Power Battery, Department of Chemistry, Northeast Normal University Changchun, 130024, China

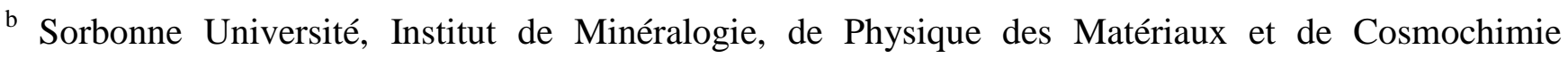
(IMPMC), CNRS UMR 7590, 4 Place Jussieu, 75005 Paris, France

${ }^{*}$ Corresponding author. E-mail address: xiehm136@nenu.edu.cn (H. Xie) 


\begin{abstract}
:
In this paper, we develop a facile UV-derived in-situ dual-reaction to prepare a flexible poly(ethylene oxide) (PEO)-based solid polymer electrolyte (SPE), which is applied for ambienttemperature all-solid-state lithium battery. By modifying the amorphous domain of PEO through crosslinking with tetraglyme (TEGDME) and introducing a rigid linear oligomer of tetraethylene glycol dimethacrylate (TEGDMA) into the matrix, a SPE is obtained with high ionic conductivity $\left(2.7 \times 10^{-4}\right.$ $\mathrm{S} \mathrm{cm}{ }^{-1}$ at $24{ }^{\circ} \mathrm{C}$ ) and enhanced mechanical strength. The as-prepared SPE shows superior electrochemical properties with decent lithium transference number of 0.56 , wide electrochemical stability window above $5 \mathrm{~V}$ vs. $\mathrm{Li}^{+} / \mathrm{Li}$ and low interfacial resistance. By means of galvanostatic cycling studies in $\mathrm{Li} / / \mathrm{Li}$ symmetrical and $\mathrm{LiFePO}_{4} / / \mathrm{Li}$ cells, we further demonstrate that the $\mathrm{SPE}$ exhibits excellent cycling performance with minimization of lithium dendrite formation.
\end{abstract}

Keywords: solid polymer electrolyte; in-situ dual-reaction; all-solid-state lithium battery; interfacial resistance.

\title{
1. Introduction
}

Lithium-ion batteries (LIBs) are considered as attractive energy storage devices because of their light weight and high-energy density [1-3]. The conventional LIBs currently use liquid organic electrolytes that can cause the potential risk of electrolyte leakage, thermal runaway, or fire hazards under the conditions of misuse, short circuit, overcharging, or local overheating $[4,5]$. In addition, the demand of practical large-scale and reliable devices has driven the development of Li metal anode, which has the highest theoretical capacity $\left(3,829 \mathrm{mAh} \mathrm{g}^{-1}\right)$ and lowest electrochemical potential $(-3.04$ $\mathrm{V}$ vs. SHE). However, the liquid organic electrolytes have a lower unoccupied molecular orbital (LUMO) below the Fermi level of alkali-metal anodes [6]. Therefore, Li metal cannot be utilized 
because of the formation of dendrite that can expand across the traditional separator and cause thermal runaway by internally short circuit, leading to fire $[7,8]$. These drawbacks have led to the development of all-solid-state Li-metal batteries [9-13], for which the use of liquid electrolytes is eliminated. Solid polymer electrolytes (SPEs) are compatible with Li-metal anode and effectively mitigate dendrite growth because SPEs are usually less reactive with Li metal [14]. However, their small electrical conductivity at room temperature and the high interfacial resistance are persistent obstacles to implementation $[15,16]$.

Poly(ethylene oxide) (PEO)-based SPEs have been studied for decades since the discovery of their fast-ionic conduction relying on the $\left(-\mathrm{CH}_{2}-\mathrm{CH}_{2}-\mathrm{O}-\right)_{n}(-\mathrm{EO}-)$ oligoether segmental motion $[17,18]$. They benefit of a high dielectric constant $(\varepsilon \approx 5)$ and a strong $\mathrm{Li}^{+}$-ion solvating ability. Unfortunately, the ionic conductivity of PEO at room temperature, $\sigma_{\mathrm{iRT}}$, is the order of $10^{-7} \mathrm{~S} \mathrm{~cm}^{-1}$, while the required value for practical applications would be $10^{-4} \mathrm{~S} \mathrm{~cm}^{-1}$. The fast ionic transport takes place in the amorphous phase above the glass transition temperature $T_{\mathrm{g}}$ but is still limited by the high degree of crystallinity as the melting point of PEO is about $65{ }^{\circ} \mathrm{C}[18,19]$. Therefore, the ordinary PEO-based electrolytes can only work at elevated temperature, and generally lose their moderate mechanical properties in the melting state where they become inhomogeneous inside the cell during cycles. Consequently, the development of a SPE with acceptable $\mathrm{Li}^{+}$-ion conductivity for use in all-solid-state lithium battery working at room temperature is highly requested. Growing research focuses on reducing the crystallinity to maintain the amorphous state of PEO-based SPEs. Many strategies have been tested, such as incorporation of ceramic or inorganic nanoparticles as fillers [20-24], introduction of roomtemperature ionic liquid [25], design of branched or star structures [26, 27], synthesis of copolymers [28-30] or single-ion conducting electrolytes [31, 32], use of new type of Li salts [33] and preparation of cross-linked polymers [34-39]. Nevertheless, the results at ambient temperature are still below the requirements for solid-state polymer electrolytes in lithium batteries, i.e. $\mathrm{Li}^{+}$ion conductivity $\geq 10^{-4} \mathrm{~S}$ 
$\mathrm{cm}^{-1}$ at $25^{\circ} \mathrm{C}$ and stable potential window $\geq 4.0 \mathrm{~V}$ vs. $\mathrm{Li}^{+} / \mathrm{Li}$. Suitable SPEs meeting these requirements without sacrificing the mechanical properties are then needed for further development of all-solid-state Li metal batteries.

With PEO-based polymers, the preferred salt is lithium bis(trifluoromethanesulfonyl)imide (LiTFSI) because its $\mathrm{Li}^{+}$cations supply the electro-active species in the electrolyte, and TFSI ${ }^{-}$anions exert a plasticizing effect on the polymer [40]. A composite SPE consisting of PEO, LiTFSI, and tetraglyme (TEGDME) was successfully used as a protective layer between lithium metal and a waterstable lithium ion-conducting glass ceramic [41]. It confirms a prior report that oxidative stability of the glyme molecules is enhanced by complex formation with LiTFSI [42]. The large increase of the conductivity obtained by introduction of the TEGDME also shows that TEGDME reduces the coordination of lithium ions with EO units by the high $M_{\mathrm{w}}$ PEO matrix, allowing the $\mathrm{Li}^{+}$ions to decouple from the ion pairs. On another hand, triethylene glycol dimethacrylate (TEGDMA) is a difunctional monomer commonly used as cross-linking agent, and forms between 30 and $50 \%$ of almost all the resins. These kinds of short monomers can be activated by UV-derived free radical photopolymerization, which is an eco-friendly, solvent-free and energy-efficient technology with low cost, and widely used in various fields because of its easily implement [43-45]. The UV-curing goes through a rapid process within minutes and easily obtains greatly improvements in different properties, while maintaining transparency and gloss.

In the present work, we have synthesized a cross-linked polymer formed from PEO, TEGDMA and TEGDME (hereafter called PTT) SPE that combines the synergetic properties of these different components with LiTFSI. The electrode/electrolyte composite was prepared by a novel in-situ UVderived dual-reaction that reduces the interfacial resistance and reinforces the performance of the electrochemical cell with $\mathrm{LiFePO}_{4}$ (LFP) cathode. A soft cross-linked polymer was obtained by the introduction of short chain organics to enhance the room-temperature ionic conductivity and 
mechanical strength at the same time. The as-introduced cognate monomers have different functions into the PEO matrix. They fabricate an internal cross-linking network and also form rigid linear chains by one-step UV-curing. Due to a disordered inner structure, the crystallinity of as-prepared SPE was reduced. These modifications resulted in enhanced ionic conductivity at ambient temperature. Moreover, the SPE product also prevents the formation of $\mathrm{Li}$ dendrite, owing to its improved mechanical strength. The interaction between $\mathrm{Li}^{+}$and $\mathrm{C}=\mathrm{O}$ polar group of TEGDMA after polymerization is beneficial to the dissociation of LiTFSI that enriches the fast charge carriers, such as free ions and ion pairs, in the SPE matrix [19]. Consequently, the ionic conductivity and lithium ion transference number should be enhanced by such structural features.

\section{Experimental section}

\subsection{Materials}

Poly(ethylene oxide) (PEO), with different average molecule weights $\left(10^{4} \leq M_{\mathrm{w}} \leq 2 \times 10^{6} \mathrm{~g} \mathrm{~mol}^{-1}\right)$ (Sigma-Aldrich), tetraethylene glycol dimethacrylate (TEGDMA, Sigma-Aldrich) and tetraethylene glycol dimethyl ether (TEGDME, Sigma-Aldrich) were used as reactants. The precursor was along with bis(trifluoromethanesulfonyl)imide lithium salt (LiTFSI, Solvay) and photoinitiator 4methylbenzophenone (MBP, Aladdin). All the chemicals were used without any purification.

\subsection{Electrodelelectrolyte composite Preparation}

The electrode/electrolyte LFP/SPE composite was prepared by a novel in-situ UV-derived dualreaction as follows. First, the reactants were mixed by stirring overnight at room temperature to get a homogenous precursor (blend) solution. Then, the precursor was successively coated onto the active LFP cathode previously deposited on aluminum foil, hot-pressed at appropriate stress $(P \approx 2 \mathrm{MPa})$ and heated at $80{ }^{\circ} \mathrm{C}$ for about 10 min with a polyethylene terephthalate (PET) film placed on the top. This film had two functions: (i) it protects the polymer membrane against moisture and (ii) it acts as scaffold 
of the liquid precursor before the completed in-situ synthesis. At this stage, the electrode/electrolyte composite was a sample in the form of sandwich in the sequence Al/LFP/PTT-SPE/PET. Similar layered architecture Teflon plate/PTT-SPE/PET was prepared by characterization of the polymer membrane. During the hot-pressing process, the precursor changed from white liquid to transparent and viscous state, and uniformly overspread the LFP electrode. The precursor was later exposed under a 500 W Hg lamp (CEL-M500, Beijing China Education Au-light co., Ltd) to initiate the in-situ dualreaction for $15 \mathrm{~min}$. The UV light with a main wavenumber of $365 \mathrm{~nm}$ was provided, and the radiation exposure energy was about $150 \mathrm{~mW} \mathrm{~cm}^{-2}$. Then, the transparent and homogeneous mixture turned into a solid-state membrane. The in-situ cured PTT-SPE was adherent to the surface of LFP in integrality, and non-tacky to plastic film (Fig. S1).

\subsection{Electrochemical measurements}

Electrochemical tests were realized using coin-type cells (CR2025) as an assembly of $\mathrm{LiFePO}_{4}$ (LFP)-based cathode, solid polymer electrolyte (or liquid-state electrolyte with PE separator) and metallic lithium foil as anode. The positive electrode was fabricated by drying a slurry of $\mathrm{LiFePO}_{4}: 350$ carbon: poly(vinylidene fluoride) $(\mathrm{PVdF})=80: 10: 10 \mathrm{wt} . \%$ deposited on aluminum foil at $120{ }^{\circ} \mathrm{C}$ in vacuum oven overnight. The active electrode material loading was $1.5 \pm 0.2 \mathrm{mg} \mathrm{cm}^{-2}$. All cells were assembled in an Ar-filled glove box (Mikrouna Super, $\mathrm{O}_{2}$ and $\mathrm{H}_{2} \mathrm{O}$ content $<0.1 \mathrm{ppm}$ ). Galvanostatic charge-discharge tests were performed on a LAND CT2001A battery testing system. The cyclic voltammograms (CV) of full cells were carried out on a P4000 electrochemical workstation at a scan rate of $0.1 \mathrm{mV} \mathrm{s}^{-1}$ in the potential range $2.5-4.3 \mathrm{~V}$. The electrochemical impedance spectroscopy (EIS) tests were measured by a P4000 workstation in the range of $1 \mathrm{MHz}-0.01 \mathrm{~Hz}$. The interfacial stability between SPE and metallic Li was checked by monitoring the evolution of the impedance values of a symmetrical cell assembled by Li metal non-blocking electrode with time at room temperature under OCV conditions. The stability of the polymer electrolyte was investigated using the symmetric SS//SS 
cell under OCV conditions. The electrochemical stability window (ESW) was measured in twoelectrode cells by cyclic voltammetry at a scan rate of $0.1 \mathrm{mV} \mathrm{s}^{-1}$. The anodic linear sweep voltammetry (LSV) was carried out from OCV to $6 \mathrm{~V}$ vs. $\mathrm{Li}^{+} / \mathrm{Li}$ with a stainless steel (SS) working electrode and $\mathrm{Li}$ metal as the counter and reference electrodes. $\mathrm{Cu}$ foil and $\mathrm{Li}$ metal were taken for the cell configuration for a $\mathrm{CV}$ scan from $\mathrm{OCV}$ to $-0.2 \mathrm{~V}$ vs. $\mathrm{Li}^{+} / \mathrm{Li}$. All the cells for tests were used without any elevated temperature pre-treatment and all the tests were measured at room temperature. After cycling, the cells were disassembled in the glove box for further post-mortem characterization.

\section{Results and discussion}

\subsection{In situ dual-reaction}

First, we explored the appropriate molecule weight $M_{\mathrm{w}}$ of PEO and the formulation of the SPE ternary blend that permit to obtain a homogeneous solution in $3 \mathrm{~mL}$ acetonitrile ( $\mathrm{ACN}$ ), which is a prerequisite to form a uniform membrane. The best solution ability was obtained for $M_{\mathrm{w}}=10^{5} \mathrm{~g} \mathrm{~mol}^{-1}$, while the condition of reaction suggests the ratio of reactants PEO: TEGDMA: TEGDME $=2: 1: 2$ wt. $\%$ with appropriate amounts of LiTFSI (EO: $\mathrm{Li}=24: 1)$. TEGDMA is a short monomer and will thus confer mechanical flexibility that provides resistance to fracture and accommodates volume changes during cycling. It will also form relatively good adhesion to electrodes (the reason why it enters in the composition of resins). On another hand, the tetraglyme molecule will act as a plasticizer that can soften the polymer and improve ion transport in the polymer phase [46], following the general trend that the introduction of low molecular weight oligomer ethers as plasticizer increases the ionic conductivity of PEO-based polymers [47]. 

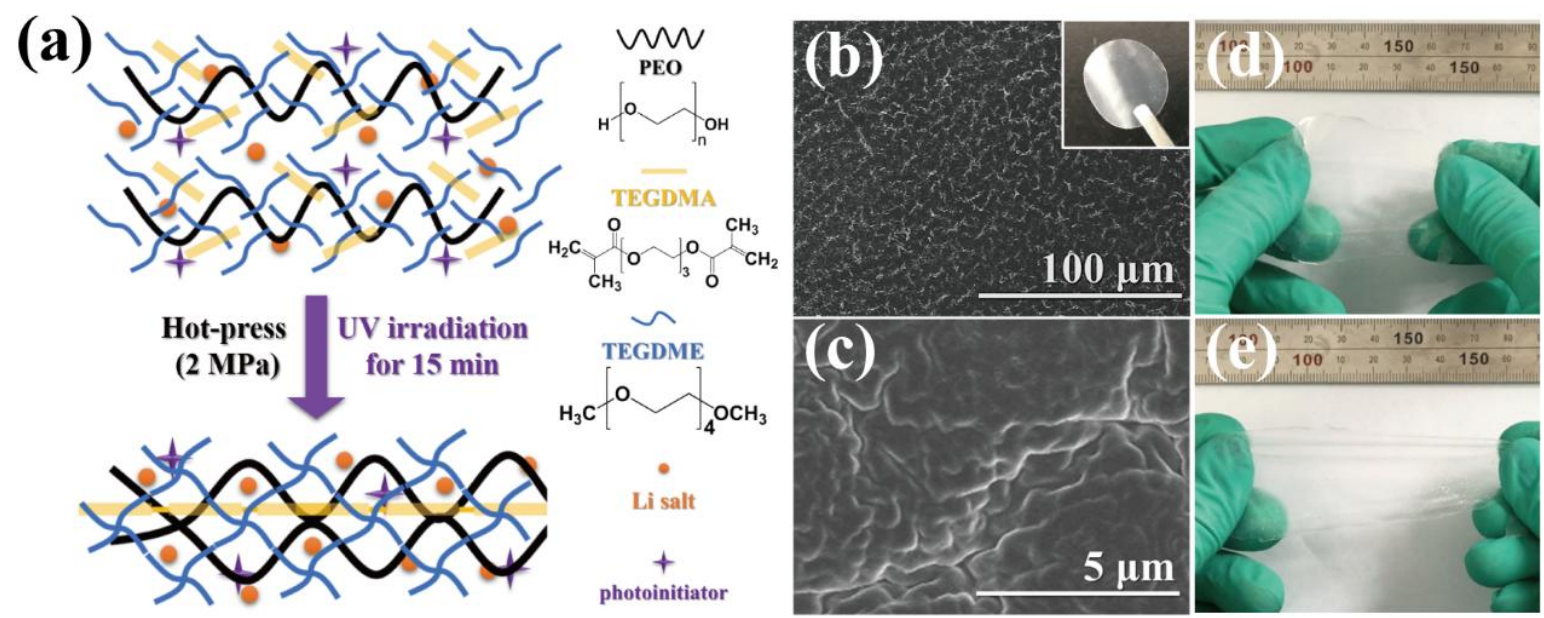

Fig. 1. (a) Diagram of inter-crosslinking structure of PTT-SPE. (b, c) SEM images of PTT-SPE membrane. (d, e) Photographs of the PTT-SPE (2:1:2) film under stretching mode.

As evoked in the Experimental Section, an original method, i.e. in-situ UV-derived dual-reaction, has been developed to prepare the PTT-SPE membrane through crosslinking and polymerization. Fig. 1a shows the schematic procedure of the in-situ reaction process involved in the synthesis of crosslinked blend electrolyte. The homogenous solution composed of the reactants above mentioned was first poured onto LFP cathode and treated by hot-pressing to solidify the thermoplastic PEO and transform the fluid precursor into a curable layer. Then, the in-situ dual-reaction occurred directly on the surface of the electrode. Under UV exposure, the $-\mathrm{C}=\mathrm{C}$ - groups of TEGDMA induce selfpolymerization and form a linear oligomer, PTEGDMA. Meanwhile, the photoinitiator is activated to attract protons from methylene groups of PEO and TEGDME (may be TEGDMA as well), thus generating free radical chains with active domain. An active site can link to another, belonging to the same -EO- chains or to other ones. This induces the rearrangement of PEO chains, the cross-linking of PEO and TEGDME, and the oligomerization of TEGDME. The PTEGDMA intersperses through the cross-linked polymer matrix and generates a rigid framework for the soft substrate. As a result of the interpenetrative architecture and the existence of oligomers, the PTT-SPE film is mainly amorphous in nature, shows excellent flexibility and good mechanical strength. 
Further details on the preparation of PTT-SPE are given in the electrode/electrolyte preparation section. The electrode/electrolyte composite was easy to handle and displayed excellent flexibility (See Fig. S1). We assume that the PTT-SPE membrane can fit the LFP particle shape during the melting process to form an optimum interface after in-situ UV-curing process (see Fig. S2a). The crosssectional field emission scanning electron microscopy (FESEM) and corresponding energy dispersive spectroscopic (EDS) mapping images of the LFP/PTT-SPE/Li metal assembly are shown in Fig. S2(be). We observe a rugged interface between PTT-SPE and LFP, which ensures an efficient contact. Furthermore, the interface between the PTT-SPE membrane and the Li metal anode demonstrates a good adhesion with reduced interfacial resistance. As designed, a highly amorphous phase of PTT-SPE can facilitate the segmental removal at ambient temperature, thus providing a high ionic conductivity and excellent electrochemical performance, as shown below. Furthermore, the in-situ formation of the LFP/PTT composite results in a reduced interfacial impedance due to a tight contact, which is the key parameter for the cell kinetics [48]. In addition, the flexible and robust PTT-SPE film can provide both a good compatibility with Li metal and a minimization of the Li dendrite formation to obtain a longterm cycle life.

Further investigation of the PTT-SPE microstructure was performed by FESEM. As shown in Fig. $\mathbf{1}(\mathbf{b}, \mathbf{c})$, the surface of PTT-SPE membrane is rough without pores or voids. It has a continuously wrinkled texture like rolling hills, which may be derived from the crosslinking domains between the polymer chains. Moreover, the highly compact microstructure indicates the SPE film is homogeneous without separated parts. This is attributed to the good solubility of PEO and Li salt in TEGDMA and TEGDME, which contain the same -EO- backbone as PEO [19]. The pictures in Fig. 1(d, e) demonstrate that the transparent PTT-SPE membrane can be stretched and turn back to the original shape after releasing the force. The overall morphology illustrates a highly flexible and elastic film, which should be beneficial to the contact of SPE with electrodes. 


\subsection{Characterization of the PTT-SPE solid electrolyte}

First, the soluble test described in the Supporting Information shows that the gel content of the PTT-SPE membrane after polymerization is about $52 \mathrm{wt} . \%$ (see Fig. S3) in good agreement with the expected value of 50\% according to the synthesis parameters. Fig. S4 shows the FTIR spectra of the PTT-SPE membrane before and after UV radiation. In the high-wavenumber region, the absorption bands at 3432 and $2877 \mathrm{~cm}^{-1}$ are attributed to the stretching vibration of -OH terminal group in PEO and to the $\mathrm{C}-\mathrm{H}$ stretching vibration, respectively. The band associated with the stretching vibration of the $\mathrm{C}-\mathrm{O}-\mathrm{C}$ group (from -EO- chains) is located at $1106 \mathrm{~cm}^{-1}$. The spectrum of polymeric components remained nearly the same with the precursor, so that the UV irradiation had no effect on the vibrational properties of the main polymeric chains above mentioned. However, as shown in Fig. 2a, we observe the disappearance of the vibration peak at $1655 \mathrm{~cm}^{-1}$ (assigned to the stretching of the $\mathrm{C}=\mathrm{C}$ on methacrylate) and the concomitant growth of the band at $1200 \mathrm{~cm}^{-1}$ (assigned to the stretching of aliphatic $\mathrm{C}-\mathrm{C}$ ), which give evidence of the full conversion of the TEGDMA monomer by reactions [49]. In addition, the $\mathrm{C}=\mathrm{O}$ vibration mode has shifted from 1718 to $1729 \mathrm{~cm}^{-1}$ in the process, which is another indication that TEGDMA underwent self-polymerization to form a linear PTEGDMA by UV irradiation and has been successfully introduced into the cross-linking structure. Note that the new peaks marked by “*” symbols in the spectrum after UV irradiation are associated to aromatic $\mathrm{C}=\mathrm{C}$ stretching modes of the photoinitiator: 4-methylbenzophenone (MBP) (see Fig. S4). The other structures in the range $1100-1350 \mathrm{~cm}^{-1}$ and circa $1060 \mathrm{~cm}^{-1}$ are associated to stretching vibrations of TFSI' [44]. 

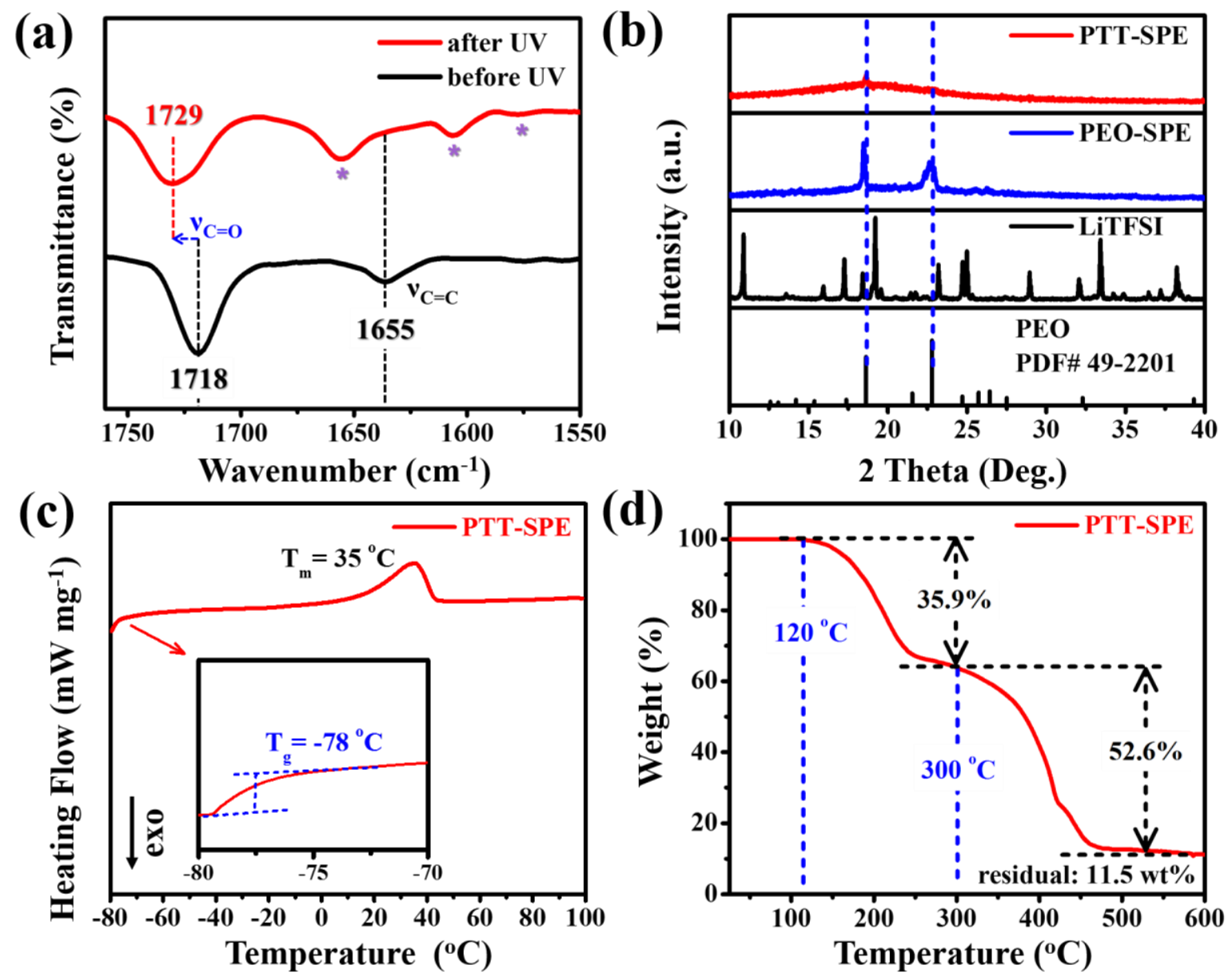

Fig. 2. Characterizations of the PTT-SPE membrane. (a) FTIR spectra of precursor (without photoinitiator) and PTT-SPE (with photoinitiator, MBP). The “*” symbols are $\mathrm{C}=\mathrm{C}$ stretching modes of MBP. (b) XRD patterns of PTT-SPE, neat PEO-SPE and LiTFSI powder. (c) DSC curve and (d) TGA profile of the PTT-SPE film.

The structural properties of SPE films were studied by XRD (see Fig. 2b). The XRD spectrum of PEO-SPE is characterized by two sharp diffraction peaks at $2 \theta=18.9^{\circ}$ and $23.1^{\circ}$, suggesting a highly crystalline phase of the neat PEO-SPE that originates from an ordering of polyether chains. These two peaks have a much smaller intensity in the PTT-SPE spectrum, which indicates a high degree of amorphization and confirms the beneficial effect of the blend. The crystallization of original PEO main chains was reduced, owing to the cross-linking and the disordered network formed by the UV-derived 
dual-reaction. Moreover, there are no peak related to LiTFSI, which means a high degree of dissociation and distribution of $\mathrm{Li}$ salt in the polymeric host. These results suggest an improved polymeric segmental motion at ambient temperature.

The differential scanning calorimetry (DSC) response in Fig. 2c shows that the glass transition temperature $T_{\mathrm{g}}$ is lower in the PTT-SPE where $T_{\mathrm{g}}=-78{ }^{\circ} \mathrm{C}$, against $-35^{\circ} \mathrm{C}$ in the original PEO-SPE [51]. For a PEO/LiTFSI electrolyte, the usual molar ratio $\mathrm{EO} / \mathrm{Li}^{+}=20$ is adopted since it affords relatively high ionic conductivities. However, even in this case, $T_{\mathrm{g}}$ was still $-45{ }^{\circ} \mathrm{C}$ [52], while a low value of $T_{\mathrm{g}}$ is the key factor for a high ionic conductivity of a polymer system used as electrolyte, especially at ambient temperature where a high degree of amorphous phase is requested. In order to further study the thermal stability of PTT-SPE, TGA measurement was carried out in the range 25-600 ${ }^{\circ} \mathrm{C}$ (Fig. 2d). The absence of weight loss indicates the stability of the electrolyte membrane is up to 120 ${ }^{\circ} \mathrm{C}$. The first sharp decrease of 35.9 wt. $\%$ until ca. $300{ }^{\circ} \mathrm{C}$ is associated with the evaporation and degradation of TEGDME and TEGDMA components. The second step after ca. $300{ }^{\circ} \mathrm{C}$ with $52.6 \%$ weight loss is mainly due to the decomposition of cross-linked PTT-SPE electrolyte and photoinitiator. The final weight appears to be $11.5 \%$ is the residual of carbon under $\mathrm{N}_{2}$ atmosphere. Taking the experimental error into consideration, the overall weight loss of $88.5 \%$ is consistent with the composition of PTT-SPE membrane.

\subsection{Electrical and electrochemical properties and stability}



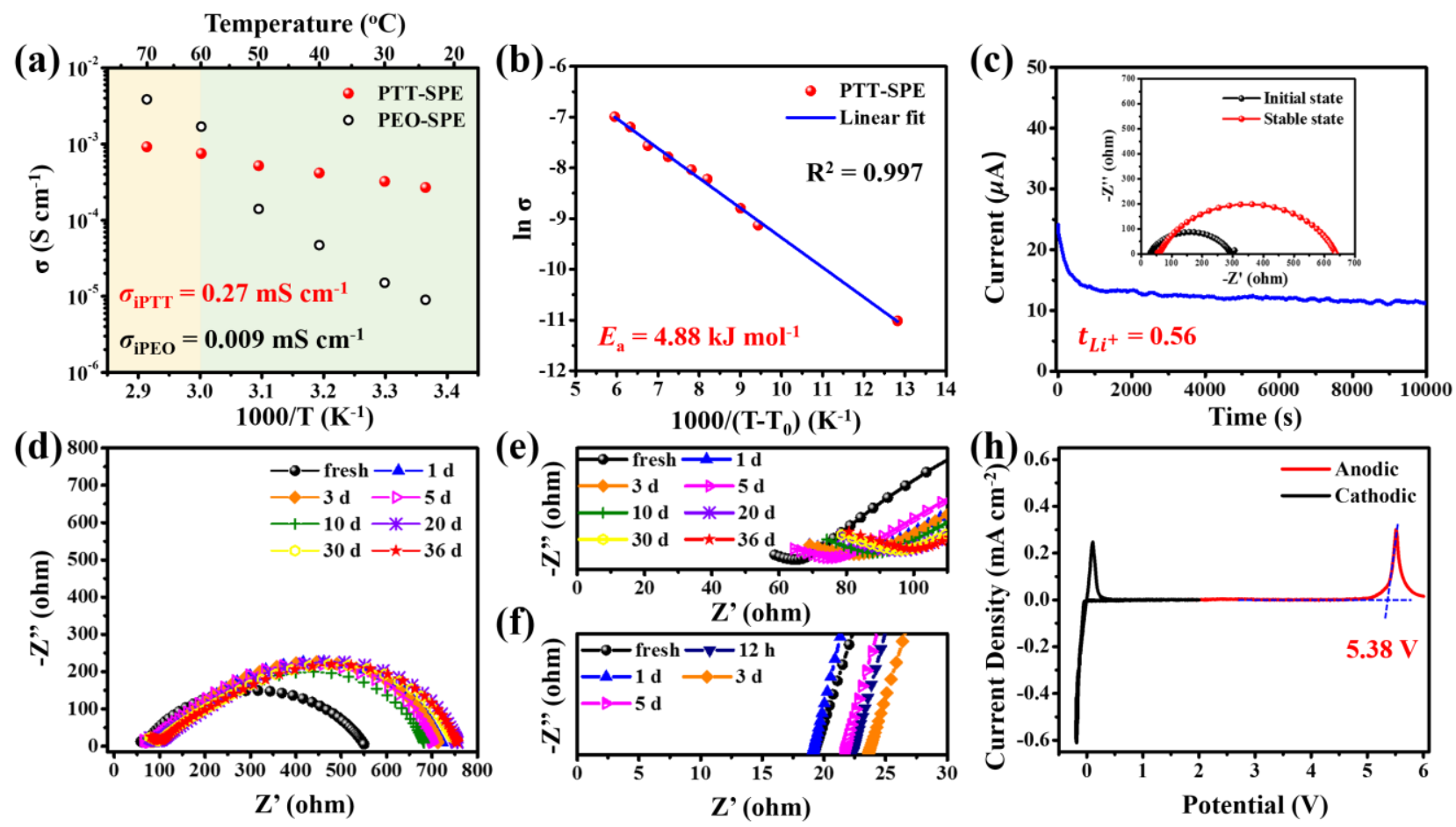

(g)

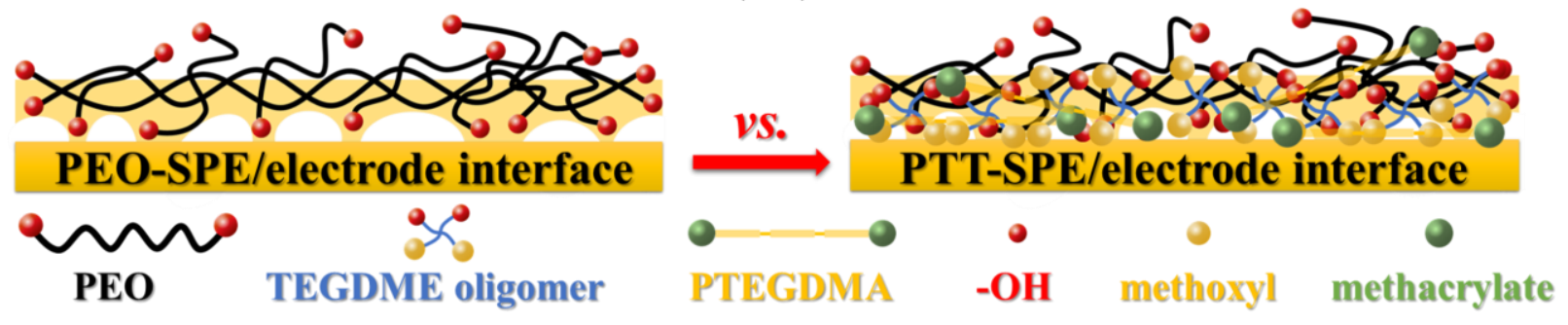

Fig. 3. Electrical and electrochemical characterizations of PTT-SPE membrane. (a) Arrhenius plot of the ionic conductivity of PTT-SPE $(2: 1: 2)$ and PEO-SPE $\left(M_{\mathrm{w}}=10^{5} \mathrm{~g} \mathrm{~mol}^{-1}\right)$. (b) Linear fit of $\ln \left(\sigma_{\mathrm{i}}\right)$ using the VTF model with $T_{0}=175 \mathrm{~K}$. (c) Chronoamperometry curve showing the time-dependence response of $10 \mathrm{mV}$ d.c. polarization for a symmetric Li/PTT-SPE/Li cell at room temperature. Inset shows the complex impedance response before and after the d.c. polarization. (d) Nyquist plots of the interfacial resistance with time for PTT-SPE using the Li/PTT-SPE/Li symmetric cell. (e) Magnification of the high-frequency region of the interfacial resistance. (f) Impedance measurements of electrolyte stability using a symmetric SS/PTT-SPE/SS cell. (g) Schematic representation of the SPE/electrode interface. (h) Electrochemical stability window (ESW) determined from anodic and cathodic scan of PPT-SPE. 
Fig. 3 presents the electrical and electrochemical properties of the as-prepared PTT-SPE membrane in terms of $\mathrm{Li}^{+}$-ion transference number, compatibility of the SPE film with the Li-metal anode and electrochemical stability window (ESW). As shown in Fig. 3a, the Arrhenius plot demonstrates the thermal activation of the ionic conductivity in the temperature range from 24 to 70 ${ }^{\circ} \mathrm{C}$. A remarkable high ionic conductivity value of $\sigma_{\mathrm{i}}=0.27 \mathrm{mS} \mathrm{cm}^{-1}$ is measured at ambient temperature $\left(T=24^{\circ} \mathrm{C}\right)$ for the as-prepared PTT-SPE membrane, which is 30 times higher than that of pristine PEO-SPE. This high conductivity of the PTT-SPE at room temperature implies a fast-ionic mobility, which is attributed to the disordered structure of interlinked polymer substrate with reduced crystalline phase. It's worth mentioning that the ionic conductivity of PTT-SPE is lower than that of PEO-SPE when the temperature gets higher than the melting point of PEO-SPE $\left(59.6{ }^{\circ} \mathrm{C}\right.$, seen in Fig. S5). This is reasonable because the PTT-SPE has a less mobile nature at high temperature after crosslinking compared with pristine PEO-SPE. This is another evidence to prove that the PTT-SPE has occurred the UV-derived dual-reaction. In order to study the conduction mechanism inside the PTTSPE, the ionic conductivity behavior was fitted using the Vogel-Tamman-Fulcher (VTF) equation:

$$
\sigma=A T^{-1 / 2} \exp \left[\frac{E_{a}}{R\left(T-T_{0}\right)}\right]
$$

where $A$ is the pre-exponential factor, which is related to the number of charge carrier, $E_{a}$ is the activation energy, $R$ is the ideal gas constant and $T_{0}$ is an equilibrium glass-transition temperature related to $T_{\mathrm{g}}$ (also named Vogel temperature). Using Eq. (1), the best fit by linear regression of $\ln \sigma_{\mathrm{i}}(T)$ vs. $T-T_{0}$ (Fig. 3b) is obtained with $T_{0}=175 \mathrm{~K}$ (correlation coefficient $R^{2}=0.997$ ). It provides a value of the activation energy $E_{a}$ of $4.88 \mathrm{~kJ} \mathrm{~mol}^{-1}(50 \mathrm{meV})$, which matches well with the high ionic conductivity and the low glass-transition temperature. At the Vogel temperature $T_{0} \approx 175 \mathrm{~K}$, the viscosity of the SPE goes to infinity; it corresponds to the state where the segmental conductivity drops to zero. Note $T_{0}=175 \mathrm{~K}=-98{ }^{\circ} \mathrm{C}$ is $20{ }^{\circ} \mathrm{C}$ below $T_{\mathrm{g}}$. This is a typical difference observed in such 
systems characterized by a critical slowing down of the motion of the viscosity. It comes from the fact that the DSC measurements detect $T_{\mathrm{g}}$ by the change in heat capacity associated to the freezing of the segmental motion. This is thus a $T_{\mathrm{g}}$ measured at the time scale of the laboratory measurements, while $T_{0}$ is measured by extrapolation as the temperature of the freezing in the infinite time limit.

The transference number for $\mathrm{Li}^{+}$ions $\left(t_{\mathrm{Li}+}\right)$ was determined from the combination of the chronoamperometry and electrochemical impedance spectroscopy (EIS) measurements before and after application of a d.c. polarization, according to the formula displayed in the section devoted to the methods (Supplementary). $t_{\mathrm{Li}+}$ and the EIS spectra are reported in Fig. 3c. $t_{\mathrm{Li+}}$ equals 0.56 for the PTTLiTFSI-SPE system at ambient temperature, a good value that can be compared with data found in the literature (Table 1). A large value of $t_{\mathrm{Li}}$ is requested for applications in batteries, as a low $t_{\mathrm{Li}+}$ would generate concentration gradients of ions and cause cell polarization that lead to a premature failure of batteries. Furthermore, a low $t_{\mathrm{Li}+}$ may induce the growth of Li dendrite and raise safety issues. Lu et al. [53] theoretically analyzed the Li dendrite formation and predicted the reduced growth using an electrolyte with high value of $t_{\mathrm{Li}+}$, which is here mainly due to the strong Li salt solvating ability of PTT-SPE and the improved $\mathrm{Li}^{+}$mobility. Generally, $\mathrm{Li}^{+}$can be present as free ions, co-existing with ion pairs and aggregates in the polymer substrate. This result also demonstrates that redundant ion pairs, or free ions and neutral ion pairs are absent in PTT-SPE. Due to the presence of $\mathrm{C}=\mathrm{O}$ groups of PTEGDMA, the coordination between $\mathrm{Li}^{+}$and $\mathrm{O}$ atom of -EO- chains is weakened, which accelerates the motion of $\mathrm{Li}^{+}$in the SPE matrix. The transference number of as-prepared PTT-SPE film is greater than that of PEO/LiTFSI blend SPEs, and comparable with that of a traditional liquid electrolyte system [54]. For comparison, the high-molecular weight PEO/LiTFSI $\left(M_{\mathrm{w}}=5 \times 10^{6} \mathrm{~g} \mathrm{~mol}^{-1}\right)$ with $\mathrm{EO} / \mathrm{Li}^{+}=20$ by mole exhibits an ionic conductivity of $1 \times 10^{-5} \mathrm{~S} \mathrm{~cm}^{-1}$ at $25{ }^{\circ} \mathrm{C}$, a $\mathrm{Li}^{+}$transference number $=0.33$ and an interface resistance much higher than the PEO/LiFSI system [42]. The $\sigma_{\mathrm{i}}$ value of our PTT-SPE film is twice that of the ethylene oxide-based polymer $\left(\sigma_{\mathrm{i}}=0.14 \mathrm{mS} \mathrm{cm}^{-1}\right.$ with $T_{\mathrm{g}}=-58$ 
${ }^{\circ} \mathrm{C}$ ) reported by Nair et al. [55] For this material the VTF analysis provided an activation energy of 6.04 $\mathrm{kJ} \mathrm{mol}^{-1}$. The single-ion BAB triblock copolymers investigated by Bouchet et al. [56] exhibits unprecedented $t_{\mathrm{Li+}}>0.85$ but the ionic conductivity is only $1.3 \times 10^{-5} \mathrm{~S} \mathrm{~cm}^{-1}$ at $60{ }^{\circ} \mathrm{C}$. Jinisha et al. [57] showed that a lithium enriched poly(ethylene oxide) (PEO)/poly(vinyl pyrrolidone) (PVP) blend polymer exhibits high $\sigma_{\mathrm{i}}$ of $1.13 \mathrm{mS} \mathrm{cm}^{-1}$ at $25{ }^{\circ} \mathrm{C}$ and $t_{\mathrm{Li}+}$ of 0.33 but the electrochemical stability is limited at 4.8 V vs. $\mathrm{Li}^{+} / \mathrm{Li}$. Further comparison with the data found in the literature [55-60] reported in Table 1 on PEO-based SPEs shows that the present result is the best compromise between $t_{\mathrm{Li}+}$ and $\sigma_{\mathrm{i}}$.

Table 1. Room temperature electrical properties of several solid polymer electrolytes with different plasticizers.

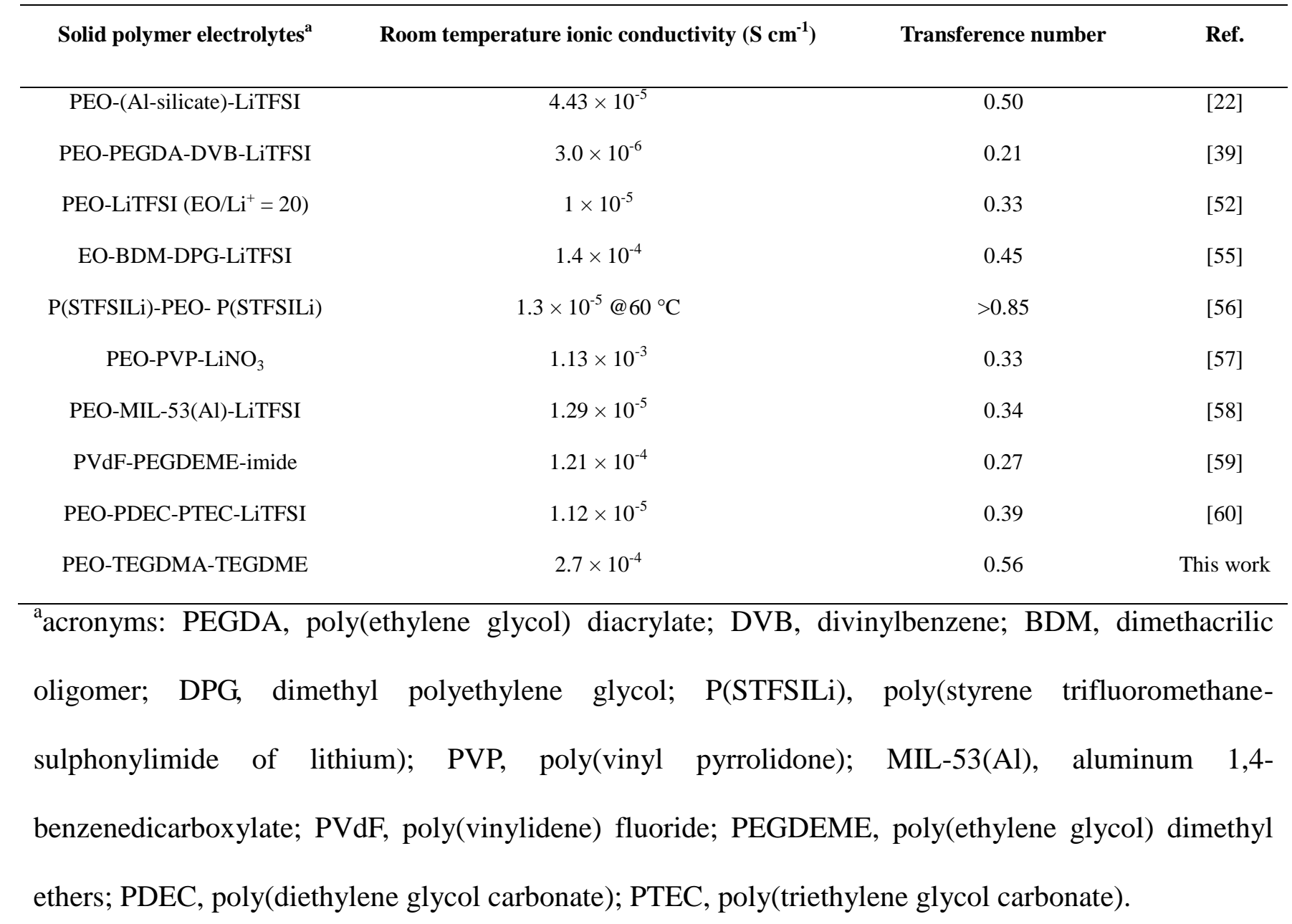


To further understand the interfacial stability of PTT-SPE with Li metal, the Li/PTT-SPE/Li symmetric cell was tested by monitoring the impedance response at ambient temperature under OCV conditions as a function of time. As shown in Fig. 3d (and magnification of the high-frequency region in Fig. 3e), the a.c. impedance spectra exhibit an incomplete arc of circle in the high-frequency region and a depressed semicircle at medium frequencies, which are associated with the resistance of the solid polymer electrolyte $\left(R_{\mathrm{SPE}}\right)$ and the reaction resistance at the electrolyte/electrode interface $\left(R_{\mathrm{E}}\right)$, respectively [61]. The equivalent circuit models for fitting the Nyquist diagrams are shown in Fig. S5 and the results are listed in Table S3. The fresh cell exhibits a $R_{\mathrm{SPE}}$ of $65 \Omega$ and a $R_{\mathrm{E}}$ of $487 \Omega$. After one day, the $R_{\mathrm{SPE}}$ increases to $80 \Omega$, the resistance of the solid-electrolyte interphase $\left(R_{\mathrm{SEI}}\right)$ equals to $249 \Omega$, and the $R_{\mathrm{E}}$ drops to $379 \Omega$ due to the wetting process of electrolyte membrane to Li metal and the formation of passivation layers. This indicates a decreasing reaction resistance by the formation of a favorable interface between PTT-SPE and Li metal. The aging of the PTT-SPE membrane was studied using a blocking symmetric cell with stainless steel (SS) electrode. Results presented in Fig. 3f show a good stability of the membrane resistance at ca. $22 \pm 3 \Omega$ after 5-day test.

As described by several authors [23, 62], PEO with high $M_{\mathrm{w}}$ tends to tangle with other chains, which results in void spaces and limited contact points between PEO and the electrode surface. The non-uniform interfacial area can facilitate the growth of $\mathrm{Li}$ dendrite, because the $\mathrm{Li}^{+}$ions are deposited or stripped through contact points. However, oligomers with smaller size can fill into voids (seen in Fig. 3g). As a result, the effective contact area between electrode and electrolyte is greatly improved. The formation of a thick and uncontrolled SEI layer can lead to a dramatic and continuous increase of cell impedance [60], whereas the reduced shift of the resistance observed in the figure is characteristic of a good compatibility of the PTT-SPE towards Li metal. Moreover, a large electrochemical stability window (ESW) of PTT-SPE is expected for the modified segment structure, as well as the existence of 
end groups such as $-\mathrm{CH}_{3}$ (TEGDME) and methacrylate (PTEGDMA) that can reduce the contact between the electrode and unstable -EO- chains and -OH terminal groups of PEO [19]. To confirm this hypothesis, the cyclic cathodic voltammogram of $\mathrm{Li} / / \mathrm{Cu}$ cells and the linear scan voltammogram of $\mathrm{Li} / / \mathrm{SS}$ cells were recorded in the voltage range from OCV to $-0.2 \mathrm{~V} \mathrm{vs}$. $\mathrm{Li}^{+} / \mathrm{Li}$ and from OCV to $6 \mathrm{~V}$ vs. $\mathrm{Li}^{+} / \mathrm{Li}$, respectively. As shown in Fig. 3h, the profile of the cathodic scan shows a superior reversibility for lithium plating and stripping, and the PTT-SPE is stable up to $5.38 \mathrm{~V} \mathrm{vs.} \mathrm{Li}^{+} / \mathrm{Li}$ according to the anodic curve. There are no redundant peaks in the curve, which gives evidence that the cross-linked polymer and oligomers have well blended and merged together. Among the recent reports, the PEOaluminosilicate composite exhibits an ESW of 4.6 V [22], the ethylene oxide-based/BDM/DPG polymer displays an anodic stability window of $4.7 \mathrm{~V}$ at $25{ }^{\circ} \mathrm{C}$. The ESW obtained by this work is the best result of a solid-state PEO-based polymer electrolyte and an appealing result for practical battery application. 

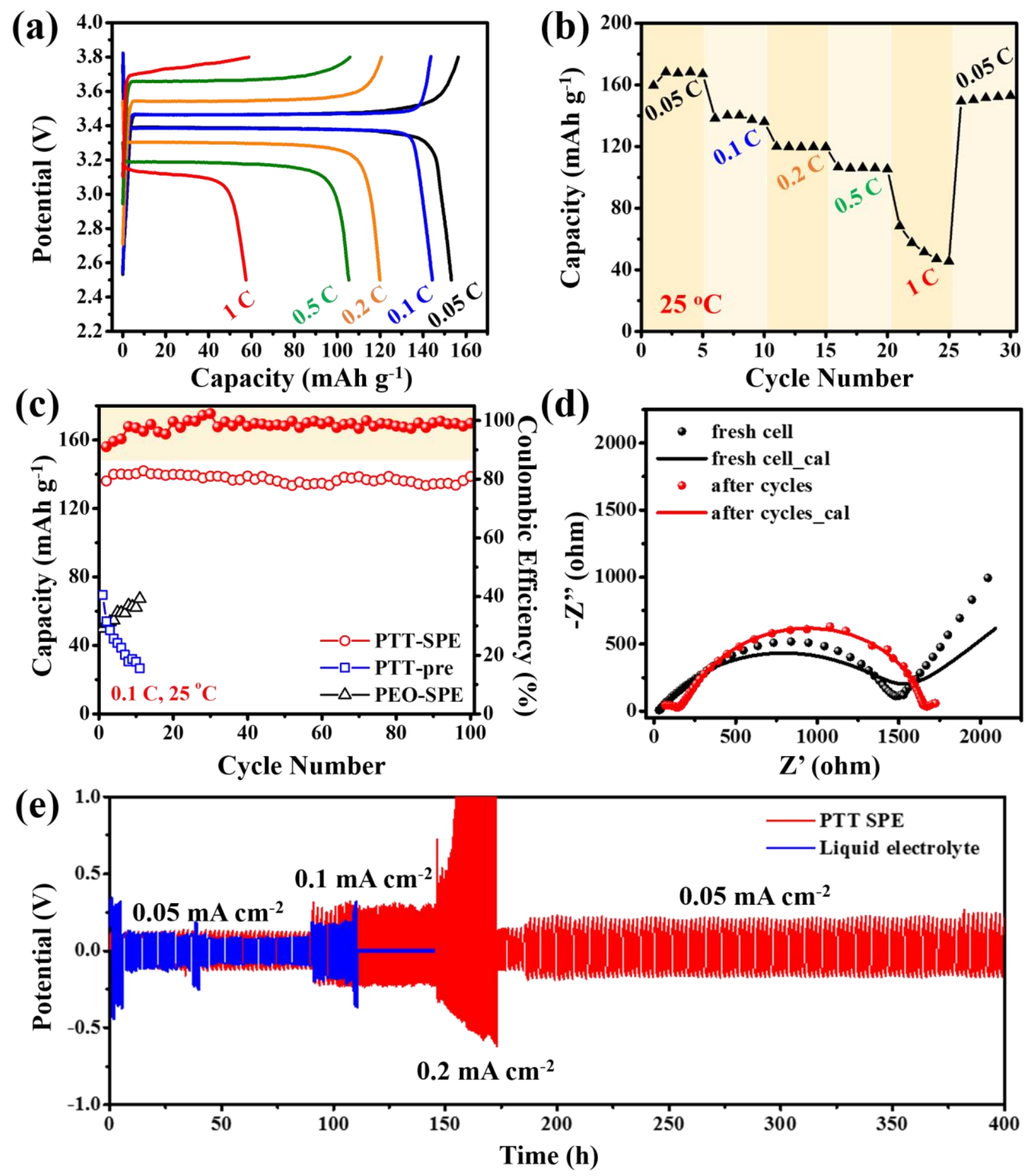

Fig. 4. LFP//Li cell performances: (a) Representative charge/discharge profiles and (b) cycle performances at different rates with PTT-SPE. (c) The long-term cycle performances of PTT-SPE, PTTpre (without UV irradiation) and PEO-SPE at 0.1 C. (d) The EIS tests of a cell with PTT-SPE before and after 100 cycles at $0.1 \mathrm{C}$. (e) The voltage profiles of Li//Li symmetric batteries with PTT-SPE and 
liquid electrolyte (1 M LiTFSI in EC/DMC) at different current density. All the measurements were carried out at ambient temperature.

The electrochemical performances of PTT-SPE membranes were investigated by assembling full cells including $\mathrm{LiFePO}_{4}$ as cathode and $\mathrm{Li}$-metal foil as anode. The representative galvanostatic chargedischarge profiles and cycling behavior of LFP/PTT-SPE/Li cells investigated at different C-rates under ambient temperature conditions are plotted in Fig. 4(a, b). The voltage polarization increases with the increasing $\mathrm{C}$-rate due to the limited $\mathrm{Li}^{+}$-ion transport kinetics. The typical plateaus and a rather limited polarization demonstrate a good reversible process (Fig. S8). As shown in Fig. 4a, the charge-discharge profiles of the LFP/PTT-SPE/Li cell at different C-rates in the range from $0.05 \mathrm{C}$ to $1 \mathrm{C}$ show the good electrochemical features with specific discharge capacities of $\sim 160$ and $\sim 60 \mathrm{mAh} \mathrm{g}^{-1}$ at $0.05 \mathrm{C}$ and $1 \mathrm{C}$ rate, respectively. The cycle ability of LFP//Li cells assembled with PTT-SPE, PTT-pre and PEO-SPE were tested at $0.1 \mathrm{C}$ (Fig. 4c) over 100 cycles. After 3 cycles, a slight increase of the specific capacity from 136 to $140 \mathrm{mAh} \mathrm{g}^{-1}$ for the LFP/PTT-SPE/Li cell is attributed to the cell formation. The capacity retention after 100 cycles is $98.8 \%$. To the contrary, the cells of PTT-pre and PEO-SPE show poor performances with low capacity and rapid capacity fading. In order to further compare the outstanding cell performances of PTT-SPE with a solid-state polymer electrolyte of room temperature, a SPE composed of PEO and TEGDME (weight ratio = 1:1) was prepared and tested at $0.05 \mathrm{C}$ for 100 cycles. As shown in Fig. S9, the capacity of LFP/PTT-SPE/Li cell increases from 151 to $160 \mathrm{mAh} \mathrm{g}^{-1}$ after a few cycles due to the cell formation. Then, this value does not change over 100 cycles. To the contrary, the capacity of the LFP/PEO+TEGDME (1:1)/Li cell changes dramatically, it decreases continuously at a rate of $2 \%$ per cycle after about 10 cycles. The outstanding cell performances of PTT-SPE membranes at ambient temperature is the synergetic effect of the disordered microstructure with low crystalline polymeric phase, a fast motion of chain-segment of polymer electrolyte, and the high value of $t_{\mathrm{Li}+}$. In addition, the restricted inner resistance at the optimum interfaces between electrolyte and 
electrodes as well as the limited overpotential are beneficial for the reduced polarization. The EIS tests of a full cell before and after 100 charge-discharge cycles at $0.1 \mathrm{C}$ were carried out to elucidate the mechanism of capacity fading. As shown in Fig. $4 \mathbf{d}$ and Table $\mathbf{S 4}$, the $R_{\mathrm{SPE}}$ increases from 31 to $151 \Omega$ after cycling. The additional semicircle arising in the high-frequency region with a value of $206 \Omega$ is attributed to the SEI resistance $R_{\mathrm{SEI}}$. A slight decrease of $R_{\mathrm{E}}$ from 1476 to $1295 \Omega$ indicates a satisfactory interfacial characteristic upon cycling, since the results imply a relatively stable component within a full cell. However, the gradually increased $R_{\mathrm{SEI}}$ resistance demonstrates that the formation of SEI might still be the dominant reason for the capacity fading at $0.1 \mathrm{C}$ rate.

It was reported that $\mathrm{Li} / / \mathrm{Li}$ non-blocking symmetric cells provide a more representative platform to describe the behavior of $\mathrm{Li}$ metal anodes $[48,63,64]$. When electrolytes are not compatible with metallic Li, or when the current distribution is not uniform as a result of inhomogeneous surface contact, the undesired formation of solid electrolyte interphase (SEI) can consume some amount of active $\mathrm{Li}^{+}$ions and cause the growth of lithium dendrite [62]. An examination of the resistance of PTTSPE against Li growth and analysis of the dendrite formation was conducted by the strip-plate test of Li//Li symmetric cells at different current densities. Fig. 4e displays the cell polarization as a function of time for a Li/PTT-SPE/Li symmetric cell. Stable voltage profiles are observed with low overpotential $\Delta E<0.5 \mathrm{~V}$ at 0.05 and $0.1 \mathrm{~mA} \mathrm{~cm}^{-2}$ without short circuit during the galvanostatic polarization tests. At $0.2 \mathrm{~mA} \mathrm{~cm}^{-2}$, the overpotential in the charging process dramatically increases and leads to a possible short circuit phenomenon, which indicates a critical current density has been reached. Typically, at a large current density, the $\mathrm{Li}^{+}$ions preferentially penetrate in the grain boundaries and voids of the solid electrolyte, where it could provide a superior reaction kinetics for Li dendrite growth [62]. However, in the present work, the potential shows a reversible tendency when the current density is decreased again. This result illustrates that the overpotential is mainly due to the limited kinetics of the PTT-SPE membrane, which causes the polarization of the cell at large current 
density under ambient temperature. During the following galvanostatic cycling, the cell delivers a flat and stable voltage plateau even after $400 \mathrm{~h}$, showing a highly reversibility and feasibility for Li dendrite inhibition. For comparison, the Li/liquid electrolyte/Li cell shows a short circuit after cycling for about $110 \mathrm{~h}$.

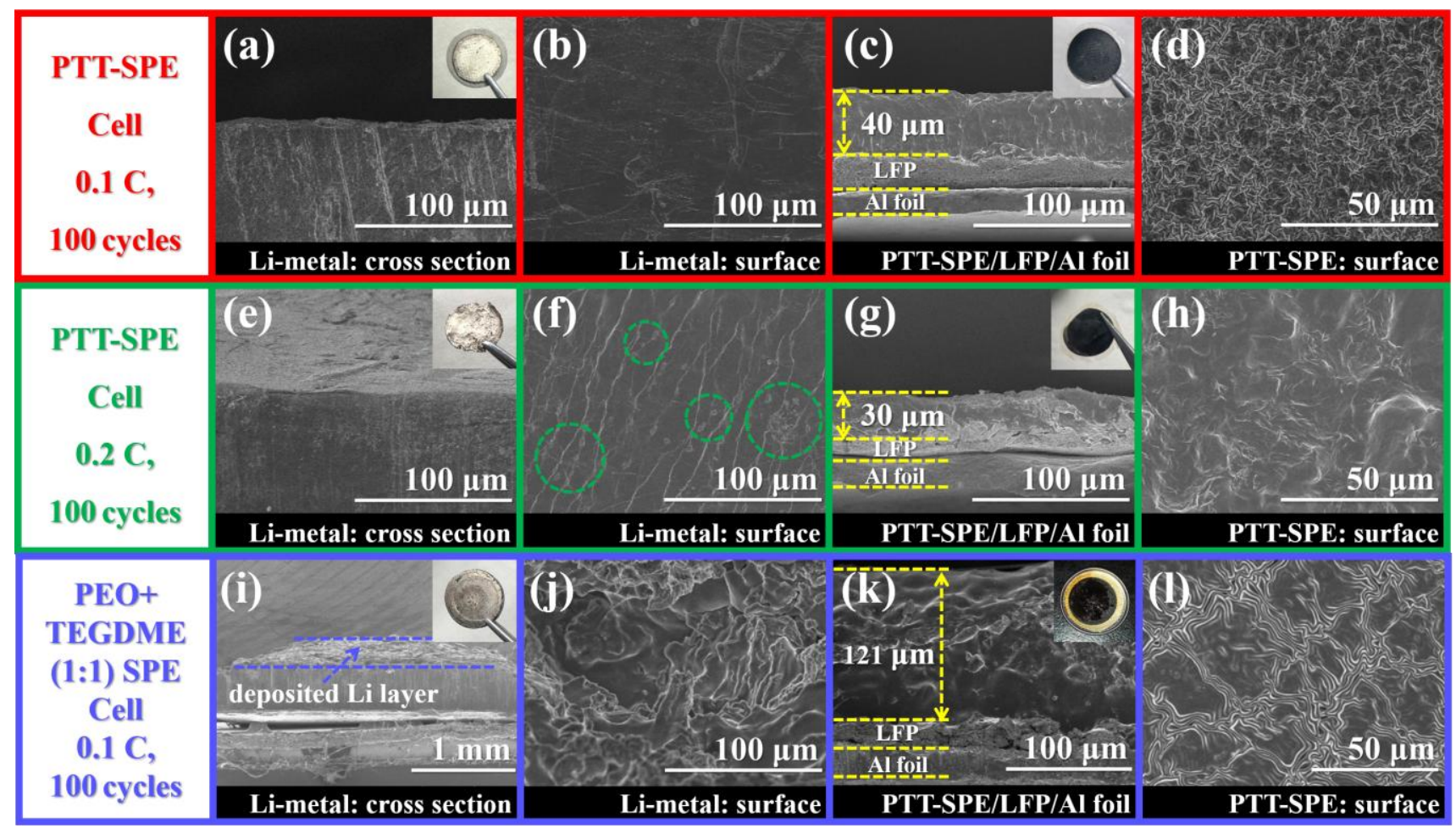

Fig. 5. Cross-sectional and plane SEM images of Li-metal anode and LFP/PTT composite after 100 charge-discharge cycles: (a-d) LFP/PTT-SPE/Li cells cycles at $0.1 \mathrm{C}$. (e-h) LFP/PTT-SPE/Li cells cycles at 0.2 C. (i-1) LFP/PEO+TEGDME (1:1) SPE/Li cells cycles at $0.1 \mathrm{C}$.

To further explore the ability of PTT-SPE membrane to hinder the Li dendrite growth in a full solid-state cell, the morphology of the cell components was investigated after cycling at $0.1 / 0.2 \mathrm{C}$ rate. The SEM images are presented in Fig. 5. The inset photograph of Fig. 5a and Fig. 5e shows that the Li metal maintains its metallic luster after cycles. The cross-sectional view of the Li anode (Fig. 5a) shows a dendrite-free morphology with a smooth surface (Fig. 5b) for the cells tested at $0.1 \mathrm{C}$. This result indicates that $\mathrm{Li}^{+}$ions have been uniformly deposited on the surface of the anode with a 
homogenous distribution at low current, due to the ultra-soft membrane with an optimum interface. Fig. 5c shows that the LFP/PTT composite keeps its integrity after cycles and there is no cleavage fracture at the electrolyte/electrode interface. Moreover, the microstructure of PTT-SPE surface keeps a lamellar morphology as pristine without any damage or phase separation (Fig. 5d). For the cells cycled at a higher current density, the surface of Li metal could maintain a commendable smoothness, even though a small amount of Li particles is growing. However, the morphology of PTT-SPE makes a change from reticular to wrinkled appearance, but still holds a homogenous distribution. For comparison, the SEM images of the PEO+TEGDME SPE system have been collected (Figs. 5i-l). After 100 charge-discharge cycles at $0.1 \mathrm{C}$ rate, the $\mathrm{Li}$ metal turns to dark and the color of electrolyte membrane changes dramatically. A thick layer of lithium was formed on the top of Li anode, and the surface of Li metal becomes rough because of the deposited (or dead) Li and Li dendrite. In addition, the morphology of the PEO+TEGDME (1:1) SPE membrane becomes inhomogeneous and is separated into different parts. It is assumed that the morphology change of SPE membrane is because of the degradation of unstable composition, which is related to the continues formation of SEI or cathode electrolyte interphase (CEI), leading to the capacity fading. The above results demonstrate a better dimensional stability and resistance against Li dendrite growth because of the compact PTT-SPE film, thus improve the safety of batteries.

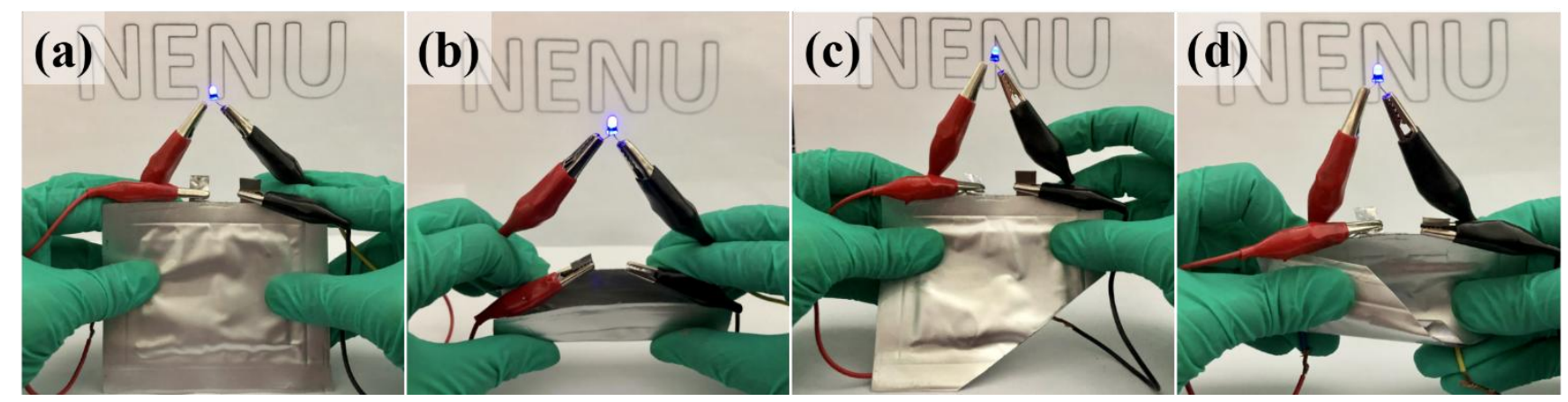

Fig. 6. Photographs for the LFP/PTT-SPE/Li soft package full cell that powers a blue LED under various condition: (a) free-bending, (b) bending, (c, d) cutting. 
Finally, in order to investigate the mechanical behavior of PTT-SPE, soft package cells consisting of LFP/PTT composite and Li anode were assembled. As shown in Fig. 6, the flexible cell is able to light up a commercial blue light-emitting diode (LED) lamp under both free-bending and bending conditions. The lamp was even still running after cutting a corner. Overall, the PTT-SPE shows an attractive practical prospect of solid-state lithium batteries working at ambient temperature.

\section{Conclusion}

We used a novel free radical photo-polymerization process to prepare a flexible solid polymer electrolyte (PTT-SPE) consisting of PEO matrix, TEGDME crosslinker and TEGDMA rigid monomer. This one-pot synthesis process is "green" in the sense that it is free of solvent, so that various issues related to the residual solvents, side reactions about interfacial stability or thermal runaway, can be avoided. For the same reason, it is also cheaper than conventional synthesis processes.

This SPE prepared via a facile UV-derived in-situ dual-reaction leads to a highly disordered structure, with a decrease of the crystallinity of PEO by the cross-linking reaction. Simultaneously, the formation of linear oligomer through self-polymerization of TEGDMA could preserve the mechanical strength of the SPE without sacrificing the ionic conductivity. The SPE was prepared in-situ on the electrode surface, which reduced the interfacial resistance. As a result, the SPE shows a high ionic conductivity of $0.27 \mathrm{mS} \mathrm{cm}^{-1}$ at $24{ }^{\circ} \mathrm{C}$ with a $\mathrm{Li}^{+}$-ion transference number of 0.56 and an outstanding electrochemical stability window extending up to $5.38 \mathrm{~V}$ vs. $\mathrm{Li}^{+} / \mathrm{Li}$. The glass temperature was decreased to $-78^{\circ} \mathrm{C}$. The ionic conductivity of the PTT-SPE membrane obeys the VTF law with an activation energy of $4.88 \mathrm{~kJ} \mathrm{~mol}^{-1}$, which reflects the excellent properties of our solid polymer. The study of Li//Li symmetrical cells demonstrates the compatibility of this SPE with lithium, and a stable voltage profile over $400 \mathrm{~h}$. The enhanced mechanical strength of PTT-SPE effectively hindered the formation of lithium dendrite. The high performance of the PEO-TEGDME-TEGDMA solid electrolyte 
was tested using LFP/PTT-SPE/Li cells at room temperature; specific discharge capacities reached values of $\sim 160 \mathrm{mAh} \mathrm{g}^{-1}$ at $0.05 \mathrm{C}$, stable over 100 cycles, and $\sim 60 \mathrm{mAh} \mathrm{g}^{-1}$ at $1 \mathrm{C}$ rate. Finally, postmortem SEM analysis of the SPE-based cells shows the absence of dendrite at the surface of the lithium metal anode after 100 charge-discharge cycles at $0.1 \mathrm{C}$. These results show that this low cost and scalable synthesis process used to prepare this new composite opens a new route to advance in the conception and realization of new solid polymer electrolytes for electrochemical energy storage.

\section{Acknowledgements}

This work was supported by Special fund of key technology research and development projects (20180201097GX) (20180201099GX) (20180201096GX), Jilin province science and technology

department. Key Subject Construction of Physical Chemistry of Northeast Normal University. The R\&D Program of power batteries with low temperature and high energy, Science and Technology Bureau of Changchun (19SS013). National Key R\&D Program of China (2016YFB0100500).

\section{Appendix A. Supplementary data}

Supplementary data: materials and characterization methods; exploration of synthesis conditions; interfaces between electrolyte and electrodes; cross-sectional FESEM image of the electrolyte/electrode interfaces; FTIR spectra of PTT-SPE; EIS measurements; analysis of the Nyquist plots; cyclic voltammograms and charge/discharge curves of LFP//Li cells.

\section{References}

[1] J.B. Goodenough, K.S. Park, J. Am. Chem. Soc., 135 (2013) 1167-1176.

[2] C.M. Julien, A. Mauger, A. Vijh, K. Zaghib, Lithium Batteries: Science and Technology, Springer, Cham, Switzerland, 2016. 
[3] V. Etacheri, R. Marom, R. Elazari, G. Salitra, D. Aurbach, Energy Environ. Sci., 4 (2011) 3243 3262.

[4] K. Xu, Chem. Rev., 104 (2004) 4303-4417.

[5] L. Cong, J. Liu, M. Armand, A. Mauger, C.M. Julien, H. Xie, L. Sun, J. Power Sources, 380 (2018) 115-125.

[6] M.H. Braga, N.S. Grundish, A.J. Murchison, J.B. Goodenough, Energy Environ. Sci., 10 (2017) 331-336.

[7] D. Lin, Y. Liu, Y. Cui, Nat. Nanotechnol., 12 (2017) 194-206.

[8] A. Hammami, N. Raymond, M. Armand, Nature, 424 (2003) 635-636.

[9] J. Janek, W.G. Zeier, Nat. Energy, 1 (2016) 1-4.

[10] A. Manthiram, X. Yu, S. Wang, Nat. Rev. Mater., 2 (2017) 16103.

[11] Q. Liu, Z. Geng, C. Han, Y. Fu, S. Li, Y.-b. He, F. Kang, B. Li, J. Power Sources, 389 (2018) 120134.

[12] J. Li, C. Ma, M. Chi, C. Liang, N.J. Dudney, Adv. Energy Mater., 5 (2015) 1401408.

[13] A. Kato, A. Hayashi, M. Tatsumisago, J. Power Sources, 309 (2016) 27-32.

[14] J. Schnell, T. Günther, T. Knoche, C. Vieider, L. Köhler, A. Just, M. Keller, S. Passerini, G. Reinhart, J. Power Sources, 382 (2018) 160-175.

[15] J. Chai, Z. Liu, J. Ma, J. Wang, X. Liu, H. Liu, J. Zhang, G. Cui, L. Chen, Adv. Sci., 4 (2017) 1600377.

[16] J. Mindemark, M.J. Lacey, T. Bowden, D. Brandell, Prog. Polym. Sci., 81 (2018) 114-143.

[17] M. Armand, Solid State Ionics, 9-10 (1983) 745-754.

[18] Z. Xue, D. He, X. Xie, J. Mater. Chem. A, 3 (2015) 19218-19253.

[19] O. Borodin, G.D. Smith, Macromolecules, 39 (2006) 1620-1629.

[20] S.-J. Kwon, D.-G. Kim, J. Shim, J.H. Lee, J.-H. Baik, J.-C. Lee, Polymer, 55 (2014) 2799-2808. 
[21] C. Gerbaldi, J.R. Nair, M.A. Kulandainathan, R.S. Kumar, C. Ferrara, P. Mustarelli, A.M. Stephan, J. Mater. Chem. A, 2 (2014) 9948-9954.

[22] W. Li, S. Zhang, B. Wang, S. Gu, D. Xu, J. Wang, C. Chen, Z. Wen, ACS Appl. Mater. Interfaces, 10 (2018) 23874-23882.

[23] K. Wen, Y. Wang, S. Chen, X. Wang, S. Zhang, L.A. Archer, ACS Appl. Mater. Interfaces, 10 (2018) 20412-20421.

[24] X. Zhang, J. Xie, F. Shi, D. Lin, Y. Liu, W. Liu, A. Pei, Y. Gong, H. Wang, K. Liu, Y. Xiang, Y. Cui, Nano Lett., 18 (2018) 3829-3838.

[25] J.-H. Shin, W.A. Henderson, S. Scaccia, P.P. Prosini, S. Passerini, J. Power Sources, 156 (2006) $560-566$.

[26] A. Wang, H. Xu, Q. Zhou, X. Liu, Z. Li, R. Gao, N. Wu, Y. Guo, H. Li, L. Zhang, Electrochimica Acta, 212 (2016) 372-379.

[27] T. Niitani, M. Amaike, H. Nakano, K. Dokko, K. Kanamura, J. Electrochem. Soc., 156 (2009) A577.

[28] C.M. Bates, A.B. Chang, N. Momčilović, S.C. Jones, R.H. Grubbs, Macromolecules, 48 (2015) 4967-4973.

[29] X. Zuo, X.-M. Liu, F. Cai, H. Yang, X.-D. Shen, G. Liu, J. Mater. Chem., 22 (2012) 22265-22271.

[30] E.D. Gomez, A. Panday, E.H. Feng, V. Chen, G.M. Stone, A.M. Minor, C. Kisielowski, K.H. Downing, O. Borodin, G.D. Smith, N.P. Balsara, Nano Lett., 9 (2009) 1212-1216.

[31] Q. Ma, H. Zhang, C. Zhou, L. Zheng, P. Cheng, J. Nie, W. Feng, Y.S. Hu, H. Li, X. Huang, L. Chen, M. Armand, Z. Zhou, Angew. Chem., Int. Ed., 55 (2016) 2521-2525.

[32] H. Zhang, C. Li, M. Piszcz, E. Coya, T. Rojo, L.M. Rodriguez-Martinez, M. Armand, Z. Zhou, Chem. Soc. Rev., 46 (2017) 797-815.

[33] Q. Ma, X. Qi, B. Tong, Y. Zheng, W. Feng, J. Nie, Y.S. Hu, H. Li, X. Huang, L. Chen, Z. Zhou, 
ACS Appl. Mater. Interfaces, 8 (2016) 29705-29712.

[34] G.T. Kim, G.B. Appetecchi, M. Carewska, M. Joost, A. Balducci, M. Winter, S. Passerini, J. Power Sources, 195 (2010) 6130-6137.

[35] R. Khurana, J.L. Schaefer, L.A. Archer, G.W. Coates, J. Am. Chem. Soc., 136 (2014) 7395-7402.

[36] L. Porcarelli, C. Gerbaldi, F. Bella, J.R. Nair, Sci. Rep., 6 (2016) 19892.

[37] L. Ma, P. Nath, Z. Tu, M. Tikekar, L.A. Archer, Chem. Mater., 28 (2016) 5147-5154.

[38] J.-C. Daigle, Y. Asakawa, A. Vijh, P. Hovington, M. Armand, K. Zaghib, J. Power Sources, 332 (2016) 213-221.

[39] H. Ben youcef, O. Garcia-Calvo, N. Lago, S. Devaraj, M. Armand, Electrochimica Acta, 220 (2016) 587-594.

[40] A. Mauger, M. Armand, C.M. Julien, K. Zaghib, J. Power Sources, 353 (2017) 333-342.

[41] H. Wang, M. Matsui, Y. Takeda, O. Yamamoto, D. Im, D. Lee, N. Imanishi, Membranes, 3 (2013) 298-310.

[42] K. Yoshida, M. Nakamura, Y. Kazue, N. Tachikawa, S. Tsuzuki, S. Seki, K. Dokko, M. Watanabe, J. Am. Chem. Soc., 133 (2011) 13121-13129.

[43] M.B. Mellott, K. Searcy, M.V. Pishko, Biomaterials, 22 (2001) 929-941.

[44] X.C. Pan, M.A. Tasdelen, J. Laun, T. Junkers, Y. Yagci, K. Matyjaszewski, Prog. Polym. Sci., 62 (2016) 73-125.

[45] D.M. He, H. Susanto, M. Ulbricht, Prog. Polym. Sci., 34 (2009) 62-98.

[46] A.S. Pandian, X.C. Chen, J. Chen, B.S. Lokitz, R.E. Ruther, G. Yang, K. Lou, J. Nanda, F.M. Delnick, N.J. Dudney, J. Power Sources, 390 (2018) 153-164.

[47] Y.T. Kim, E.S. Smotkin, Solid State Ionics, 149 (2002) 29-37.

[48] K. Fu, Y. Gong, B. Liu, Y. Zhu, S. Xu, Y. Yao, W. Luo, C. Wang, S.D. Lacey, J. Dai, Y. Chen, Y. Mo, E. Wachsman, L. Hu, Sci. Adv., 3 (2017) e1601659. 
[49] I.E. Ruyter, S.A. Svendsen, Acta Odontologica Scandinavica, 36 (1978) 75-82.

[50] I. Rey, J.C. Lassegues, J. Grondin, L. Servant, Electrochimica Acta, 43 (1998) 1505-1510.

[51] A. Vallée, S. Besner, Prud'Homme, Electrochimica Acta, 37 (1992) 1579-1583.

[52] H. Zhang, C. Liu, L. Zheng, F. Xu, W. Feng, H. Li, X. Huang, M. Armand, J. Nie, Z. Zhou, Electrochimica Acta, 133 (2014) 529-538.

[53] Y. Lu, M. Tikekar, R. Mohanty, K. Hendrickson, L. Ma, L.A. Archer, Adv. Energy Mater., 5 (2015) 1402073.

[54] R. Zahn, M.F. Lagadec, M. Hess, V. Wood, ACS Appl. Mater. Interfaces, 8 (2016) 32637-32642.

[55] J.R. Nair, D. Cíntora-Juárez, C. Pérez-Vicente, J.L. Tirado, S. Ahmad, C. Gerbaldi, Electrochimica Acta, 199 (2016) 172-179.

[56] R. Bouchet, S. Maria, R. Meziane, A. Aboulaich, L. Lienafa, J.-P. Bonnet, T.N.T. Phan, D. Bertin, D Gigmes, D. Devaux, R. Denoyel, M. Armand, Nat. Mater., 12 (2013) 452-457.

[57] B. Jinisha, KM. Anilkumar, M. Manoj, V.S. Pradeep, S. Jayalekshmi, Electrochimica Acta, 235 (2017) 210-222.

[58] K. Zhu, Y. Liu, J. Liu, RSC Adv., 4 (2014) 42278-42284.

[59] K.M. Abraham, Z. Jiang, B. Carroll, Chem. Mater., 9 (1997) 1978-1988.

[60] W. He, Z. Cui, X. Liu, Y. Cui, J. Chai, X. Zhou, Z. Liu, G. Cui, Electrochimica Acta, 225 (2017) 151-159.

[61] G. Oh, M. Hirayama, O. Kwon, K. Suzuki, R. Kanno, Chem. Mater., 28 (2016) 2634-2640.

[62] S.-S. Chi, Y. Liu, N. Zhao, X. Guo, C.-W. Nan, L.-Z. Fan, Energy Storage Materials, (2018) in press. DOI: https://doi.org/10.1016/j.ensm.2018.07.004

[63] K.N. Wood, E. Kazyak, A.F. Chadwick, K.H. Chen, J.G. Zhang, K. Thornton, N.P. Dasgupta, ACS Cent. Sci., 2 (2016) 790-801.

[64] L. Yang, Z. Wang, Y. Feng, R. Tan, Y. Zuo, R. Gao, Y. Zhao, L. Han, Z. Wang, F. Pan, Adv. Energy 
Mater., 7 (2017) 1701437. 